\title{
6个耐旱树种木质部结构与栓塞脆弱性的关系
}

\author{
李 荣 ${ }^{1}$ 党 维 ${ }^{1}$ 蔡 靖 1,3 张硕新 ${ }^{1,3}$ 姜在民 ${ }^{2 *}$
}

${ }^{1}$ 西北农林科技大学林学院, 陕西杨凌 $712100 ;{ }^{2}$ 西北农林科技大学生命科学学院, 陕西杨凌 $712100 ;{ }^{3}$ 陕西秦岭森林生态系统国家野外科学观测研究 站, 陕西杨凌 712100

\begin{abstract}
摘 要 木质部栓塞脆弱性对干旱响应的研究已成为全球气候变化背景下的热点和重要内容。该文以 6 个耐旱树种刺槐 (Robinia pseudoacacia)、沙棘(Hippophae rhamnoides)、榆树(Ulmus pumila)、元宝枫(Acer truncatum)、旱柳(Salix matsudana)、 榛(Corylus heterophylla) 为研究对象, 采用Cochard Cavitron离心机技术建立木质部栓塞脆弱曲线, 计算木质部栓塞脆弱性, 利 用染色法、硅胶注射法等测定木质部导管直径、导管内径跨度、导管连接度、导管密度、导管长度和木质部密度, 探究木质 部结构与栓塞脆弱性的关系，区分 6 个而旱树种木质部结构在抗栓塞性上的差异，以期建立6个耐旱树种在木质部结构方面的 抗栓塞性指标。结果表明: 6 个而旱树种木质部栓塞脆弱性大小为刺槐 $>$ 榆树 $>$ 沙棘 $>$ 旱柳 $>$ 元宝枫 $>$ 榛, 其中, 刺槐、沙棘和榆 树的栓塞脆弱曲线为“ $\mathrm{r}$ ”形, 而元宝枫、旱柳和榛的栓塞脆弱曲线为“s”形, 脆弱曲线为“ “ $\mathrm{r}$ ”形的树种与脆弱曲线为“ “s”形的树种 栓塞脆弱性差异极显著 $(p<0.01)$ 。线性分析表明: 木质部结构影响各树种的栓塞脆弱性, 其中, 木质部密度影响最大 $(t=$ $0.702)$, 导管直径次之 $(t=0.532)$, 导管长度影响最小 $(t=0.010)$ 。
\end{abstract}

关键词 栓塞脆弱性; 栓塞脆弱曲线; 木质部结构; 耐旱树种

引用格式: 李荣, 党维, 蔡靖, 张硕新, 姜在民 (2016). 6个耐旱树种木质部结构与栓塞脆弱性的关系. 植物生态学报, 40, 255-263. doi: $10.17521 /$ cjpe.2015.0260

\section{Relationships between xylem structure and embolism vulnerability in six species of drought tolerance trees}

LI Rong ${ }^{1}$, DANG Wei ${ }^{1}$, CAI Jing ${ }^{1,3}$, ZHANG Shuo-Xin ${ }^{1,3}$, and JIANG Zai-Min ${ }^{2 *}$

${ }^{1}$ College of Forestry, Northwest A\&F University, Yangling, Shaanxi 712100, China; ${ }^{2}$ College of Life Sciences, Northwest A\&F University, Yangling, Shaanxi 712100, China; and ${ }^{3}$ Qinling National Forest Ecosystem Research Station, Yangling, Shaanxi 712100, China

\section{Abstract}

Aims The study of embolism vulnerability to drought has become a hot and key topic under global climate change. The objective of the study was: 1) to identify the relationship between xylem structure and embolism vulnerability; 2) to define the differences in resistance of embolism in xylem structure of each species; and 3) to establish drought tolerance indexes in xylem structure of six species.

Methods Drought tolerance trees of Robinia pseudoacacia, Hippophae rhamnoides, Ulmus pumila, Corylus heterophylla, Salix matsudana, Acer truncatum were studied. Cochard Cavitron centrifuge was used to establish embolism vulnerability curves and to calculate xylem vulnerability value. Staining and silicone injection techniques were used to to measure xylem structure of drought tolerance trees including vessel diameter, conduit wall span, number of vessels per unit area, contact faction, vessel length and wood density.

Important findings The results showed: 1) xylem embolism vulnerability of the six species ranked as Robinia pseudoacacia $>$ Ulmus pumila $>$ Hippophae rhamnoides $>$ Salix matsudana $>$ Acer truncatum $>$ Corylus heterophylla; 2) the vulnerability curves is " $r$ " shape for Robinia pseudoacacia, Hippophae rhamnoides, Ulmus pumila and is "s" shape for Corylus heterophylla, Salix matsudana, Acer truncatum, respectively; 3) the xylem vulnerability values is significantly different in trees of " $\mathrm{r}$ " shape and "s" shape $(p<0.01)$. Furthermore, linear analysis showed that the different effects between the xylem structure of the species was closely related to the vulnerability in the following order: the maximum effect was from wood density $(t=0.702)$, the medium effect was from vessel diameter $(t=0.532)$, and the minimum effect was from vessel length $(t=0.01)$.

Key words embolism vulnerability; vulnerability curve; xylem structure; drought tolerance trees

收稿日期Received: 2015-07-08 接受日期Accepted: 2016-01-17

* 通信作者Author for correspondence (E-mail: jiangzmz@163.com) 
Citation: Li R, Dang W, Cai J, Zhang SX, Jiang ZM (2016). Relationships between xylem structure and embolism vulnerability in six species of drought tolerance trees. Chinese Journal of Plant Ecology, 40, 255-263. doi: 10.17521/cjpe.2015.0260

干旱是全球性的自然灾害, 近年来因干旱引起 的森林枯梢及死亡已严重影响许多国家的森林生态 系统(Maherali et al., 2004)。在我国, 干旱限制了干 旱半干旱地区植物的生长和生态修复, 生长在干旱 半干旱地区的植物在其生命周期内经常遭遇水分的 胁迫(Chaves et al., 2002; Rennenberg et al., 2006; Nahm et al., 2007), 由干旱引起的木质部空穴化和 栓塞则是制约树木生长发育和生态修复的一个重要 因素, 干旱胁迫导致的抗栓塞性在不同树种和不同 生态系统表现不同(Delzon et al., 2010), 在全球气 候变化的大背景下, 干旱导致的抗栓塞性的研究已 越来越重要(Cochard et al., 2013)。木质部栓塞是木 本植物在干旱环境下遭受水分胁迫时产生的木质部 导管输水功能障碍, 而植物对木质部栓塞的易受性 可用“脆弱曲线(VC)”来描述(Tyree \& Sperry, 1989), 该曲线是根据木质部导水率损失的百分数(PLC)与 相对应水势绘制而成的曲线, 且绝大多数脆弱曲线 可用单威布尔累积分布函数 $(\mathrm{CDF})$ 较好地拟合, 栓 塞脆弱性一般用引起枝条 $50 \%$ 导水率损失的压力值 $\left(P_{50}\right)$ 来表示。Cochard等(2008)和Awad等(2010)通过 对蓄薇科李属(Prunus)的10个树种和杨属(Populus) 的 2 个树种进行栓塞脆弱曲线的测定以及不同干旱 条件的处理, 认为抗栓塞性可作为评估植物抵御干 旱环境的一个指标。Choat等(2012)和Anderegg等 (2013)研究认为抗栓塞性的大小是评估森林生产力 和干旱导致的死亡率的一项重要生理指标, 树木栓 塞抗性的研究将会有很大发展, 这些研究也将被运 用到模型当中, 以估算植物生产力 (生理生态模型) 以及物种分布(生物地理学模型)。张硕新等(1997) 对我国北方 5 种抗旱树种栓塞脆弱性的研究表明, 耐旱的刺槐 (Robinia pseudoacacia) 和沙棘 (Hippophae rhamnoides) 是栓塞脆弱性较大、较易发生栓 塞的树种, 在水势下降时木质部导水率急剧下降, 即木质部很快发生栓塞, 而植物栓塞脆弱性与木质 部结构密切相关(Wheeler et al., 2005; Sperry et al., 2006; Hacke \& Jansen, 2009; Cai \& Tyree, 2010; 张 海听等, 2013), 植物栓塞脆弱性与木质部结构关系 的研究是了解耐旱树种抗旱机制的一个有效途径。

研究表明木质部导管的导水率与导管直径的四
次方成正比(Hagen-Poiseuille方程)(Tyree \& Zimmermann, 2002), 即导管直径越大, 导管的导水能 力就越强。多数研究认为木质部导管直径与栓塞脆 弱性正相关，即同一树种内大径导管比小径导管更 易发生栓塞(Hargrave et al., 1994; Gullo et al., 1995; Wheeler et al., 2005; Hacke et al., 2006; Cai \& Tyree, 2010; 张海昕等, 2013), 但也有研究表明栓塞脆弱 性与导管直径成反比(Lemoine et al., 2002; Hacke et al., 2009)或不相关(Rosner et al., 2007; Fichot et al., 2010)。Cai和Tyree (2010)以杨属植物为例, 按照植 物导管直径径级构建的栓塞脆弱曲线表明: 随着导 管直径增大, $P_{50}$ 值增大(负值), 即导管直径与 $P_{50}$ 呈 正相关关系。Cai等(2010b)的研究表明同一树种内 导管直径与导管长度正相关, 即大径级导管其导管 长度也越长, 张海昕等(2013)通过对 4 个杨树无性系 的研究得出相同结论。此外, 有研究表明木质部密 度和导管内径跨度(Hacke et al., 2001; Jacobsen et al., 2005; Cochard et al., 2008)、导管密度和导管连 接度等与栓塞脆弱性具有一定的相关性(Wheeler et al., 2005; Hacke et al., 2006; Cai et al., 2014)。安峰和 张硕新(2005)对刺槐、元宝枫(Acer truncatum)、榛 (Corylus heterophylla)等研究表明，同一树种小枝和 根的栓塞脆弱性主要由木质部结构决定, 小枝易发 生栓塞的, 其根也较易发生栓塞, 根和小枝的栓塞 脆弱性与植物的抗栓塞性有关。但目前, 通过木质 部结构与栓塞脆弱性的关系来说明分布于我国干旱 半干旱地区的耐旱树种在木质部结构上的差异尚未 见报道, 因此, 本研究通过采用Cochard Cavitron离 心机技术(仅需一根枝条且在 $0.5 \mathrm{~h}$ 之内即可建立一 条完整的栓塞脆弱曲线)(Cochard, 2002; Cochard et $a l ., 2005)$ 建立 6 个耐早树种栓塞脆弱曲线, 计算其 木质部 $P_{50}$, 找出 6 个耐旱树种木质部结构间的差异, 以期获得耐旱树种在木质部结构上的抗栓塞性指 标, 为干旱、半干旱地区植被恢复工作中选育节水 耐旱树种提供新的理论基础。

\section{1 材料和方法}

\section{1 研究区自然概况}

试验地选取在西北农林科技大学校园和博览园 
$\left(34.27^{\circ} \mathrm{N}, 108.07^{\circ} \mathrm{E}\right.$, 海拔 $\left.457 \mathrm{~m}\right)$, 样地处于关中平 原中部, 属半干旱地区, 暖温带大陆性季风气候, 四 季分明, 雨热同季。年平均气温 $12.9{ }^{\circ} \mathrm{C}$, 最热月(7月) 平均气温 $25.8{ }^{\circ} \mathrm{C}$, 最冷月 $\left(1\right.$ 月)平均气温 $-1.1{ }^{\circ} \mathrm{C}$, 年 极端最高气温 $42{ }^{\circ} \mathrm{C}$, 年极端最低气温 $-19.4{ }^{\circ} \mathrm{C}, \geqslant 0$ ${ }^{\circ} \mathrm{C}$ 积温 $4903{ }^{\circ} \mathrm{C}$, 持续天数 309 天, $\geqslant 10{ }^{\circ} \mathrm{C}$ 积温 4185 ${ }^{\circ} \mathrm{C}$, 持续天数 206 天, 无霜期 221 天，年降水量 651 $\mathrm{mm}$, 生长季(4-9月份)降水量占全年降水量的 $79 \%$ 。

\section{2 材料}

选取西北农林科技大学校园、博览园内自然状 况下生长良好的耐旱树种刺槐、沙棘、榆树(Ulmus pumila)、榛、旱柳(Salix matsudana)、元宝枫为研究 对象, 各树种所处立地条件基本一致。于2014年 8-10月在清晨在树冠中部北向剪取一年生枝条, 所 剪枝条基部直径6-8 mm，长30-50 cm，迅速放入装 有湿纸的黑色塑料袋中(防止水分散失和外界空气 等进入被切开的导管内), 立即带回实验室。

\section{3 研究方法}

\subsection{1 木质部栓塞脆弱性测定}

将清晨采回的枝条浸入事先装有水的容器中, 在水下用刀片切掉枝条叶柄后从中部截取 $27.4 \mathrm{~cm}$ 长枝段(枝条剩余部分用于导管直径、木质部密度等 的测定, 保证它们与测定 $P_{50}$ 的枝条为同一根枝条), 在 $0.12 \mathrm{MPa}$ 的压力下用 $100 \mathrm{mmol} \cdot \mathrm{L}^{-1} \mathrm{KCl}$ 溶液冲洗 $30 \mathrm{~min}$ 去气, 去除枝条在自然状态下及采样时人为 诱导产生的栓塞, 然后将枝段迅速放入 Cochard Cavitron离心机(Allegra X-22R, Beckman Coulter, Washington, USA)(Cochard, 2002; Cochard et al., $2005)$, 在 $0.12 \mathrm{MPa}$ 的起始压力下离心 $30 \mathrm{~min}$, 从而 获得一个稳定的最大导水率 $\left(K_{\max }\right)$ 。通过控制离心机 的转速从而形成从低到高的压力梯度 $(T, \mathrm{MPa})$, 计 算机记录不同压力下的导水率值 $\left(K_{\mathrm{h}}\right)$, 则不同压力 梯度下导水率损失百分数(percentage loss of hydraulic conductivity, $P L C)$ 的计算公式为:

$$
P L C=100\left(K_{\max }-K_{\mathrm{h}}\right) / K_{\text {max }}
$$

式中 $K_{\max }$ 为在压力最小时的最大导水率值。根据不 同压力及不同压力下所对应的导水率损失值建立植 物的木质部栓塞脆弱曲线。

曲线能够较好地拟合单威布尔累计分布函数 (CDF), 即:

$$
f(T ; b, c)=\exp \left[-\left(\frac{T}{b}\right)^{c}\right]
$$

$b$ 和 $c$ 是符合 $\mathrm{CDF}$ 的常量, $T$ 为压力。 $P L C$ 可转换为:

$$
\frac{P L C}{100}=1-f(T ; b, c)=1-\exp \left[-\left(\frac{T}{b}\right)^{c}\right]
$$

曲线拟合后可得到最适的 $b 、 c$ 值, 栓塞脆弱性 一般用 $P_{50}$ 来表示, 由公式:

$$
P_{50}=b[\ln (2)]^{1 / c}
$$

计算得出。每树种选取 5 个来自不同个体树上的枝条 进行测定，其平均值即为每树种的 $P_{50}$ 值。

\subsection{2 木质部导管直径测定}

用Leica RM2235切片机在每个枝条的横切面 上切取 $20 \mu \mathrm{m}$ 厚的完整的薄片，切片用浓度为 $0.1 \%$ 番红染料(Basic Fuchsin)染色 $1 \mathrm{~min}$, 染色完成后将 切片放入清水中漂洗浮色，然后用不同浓度梯度的 酒精(30\%、50\%、75\%、90\%)对切片依次脱水处理， 制成临时装片，放在Leica DM4000B正置荧光显微 镜 $100 \times$ 或 $200 \times$ 下获取导管直径照片(每个切面上选 取均匀分布的 3 个扇面, 每个扇面沿射线细胞方向 由木质部外侧向内侧髓心方向拍照), 所获取照片 用Win-CELL 2007软件测量导管面积, 每个枝条的 横切面至少测量400-600个导管, 根据导管横切面 面积与直径的关系计算出每个横切面积所对应的导 管直径 $(D)$ :

$$
D=\sqrt{4 A / \pi}
$$

式中 $A$ 为所测量的每个导管的横切面积 (lumen area)。5个枝条的导管直径平均值即为每树种的平均 导管直径。

\subsection{3 木质部导管内径跨度测定}

取同样测量导管直径的照片, 用 Win-CELL 2007图像分析软件测量每个横切面上相连导管的内 径跨度 $(b)$ (Hacke et al., 2001)。5 个枝条的导管内径 跨度平均值即为每树种的平均导管内径跨度。

\subsection{4 木质部导管连接度测定}

取同样测量导管直径的照片，用Win-CELL 2007图像分析软件测量每个扇面中导管与导管之间 相连长度占该扇面中所有导管周长的比例, 即导管 连接度 $\left(C_{\mathrm{f}}\right)$ (Wheeler et al., 2005)。5 个枝条的导管连 接度平均值即为每树种的平均导管连接度。

\subsection{5 木质部导管密度测定}

取同样测量导管直径的照片, 用 Win-CELL 2007图像分析软件统计出单位面积内导管数目和横 
截面的面积, 由此可得导管密度 $(N)$ (Cai et al., 2014):

$N=$ 横截面所有导管的数量/横截面的面积

5 个枝条的导管密度平均值即为每树种的导管 密度。

\subsection{6 木质部导管长度测定}

用硅胶注射法进行导管长度的测定(Wheeler et al., 2005; Hacke et al., 2007; Cai et al., 2010a) : 将清 晨采回的枝条 (长度30-50 cm) 用刀片将切面切平, 然后在 $0.12 \mathrm{MPa}$ 压力下用 $100 \mathrm{mmol} \cdot \mathrm{L}^{-1}$ 去气 $\mathrm{KCl}$ 溶 液冲洗枝条30 $\mathrm{min}$ 。硅胶配置: 硅胶是硅胶树脂和 固化剂以 $10: 1$ 混合而成(15 g RTV141 part A + $1.5 \mathrm{~g}$ RTV141 part B), $0.025 \mathrm{~g}$ 荧光增白剂Uvitex (使硅胶 在紫外光下可见)与 $2.5 \mathrm{~mL}$ 氯仿溶解后取 15 滴与硅 胶混合，搅拌使二者混合均匀后静置 $1 \mathrm{~h}$ 以除去硅胶 中的气泡。从枝条冲洗端橡胶管注入硅胶(硅胶占橡 胶管的 $2 / 3$ 即可), 在 $0.12 \mathrm{MPa}$ 压力下持续注射 $24 \mathrm{~h}$, 之后在室温 $22{ }^{\circ} \mathrm{C}$ 条件下干燥2-3天, 干燥后切片(厚 度 $20 \mu \mathrm{m})$, 切片分别从距离注射硅胶端的 $0.2 、 0.3$ 、 $0.5 、 1.0 、 1.5 、 2.0 、 3.0 、 4.0 \mathrm{~cm}$ 直到被注射导管个 数占整个扇面导管个数的 $2 \%$ 为止, 选取被注射上 导管均匀分布的 3 个扇面获取照片(操作同上)。所得 照片用Win-CELL 2007图像分析软件统计出单位面 积内被硅胶注射的导管数目, 由此可得单位横截面 内导管的数量 $(N=$ 横截面所有被硅胶注射导管的数 量/横截面的面积)。以截面到注射端的距离 $x$ 为横坐 标, 以 $\ln N$ 为纵坐标进行线性拟合, 得出线性拟合图 的斜率 $\lambda_{\mathrm{v}}$ (Cohen et al., 2003)。

上述变量之间的关系符合:

$$
N=N_{\mathrm{o}} \exp \left(\lambda_{\mathrm{v}} x\right)
$$

式中, $N_{\mathrm{o}}$ 为距离注射端 $x=0.2 \mathrm{~cm}$ 处单位面积的导管 数量, $N$ 为距离注射端 $x>0 \mathrm{~cm}$ 处横截面上单位面积 的导管数量, $\lambda_{\mathrm{V}}$ 是拟合系数 (由于指数衰减, 通常为 负值)。

由公式(7)的二次微分可以给出下面的概率分 布函数:

$$
P_{x}=x \lambda_{\mathrm{v}}{ }^{2} \exp \left(\lambda_{\mathrm{v}} x\right) \mathrm{d} x
$$

式中, $P_{x}$ 是导管在长度为 $x$ 区间内的概率。公式 $(8)$ 是 一个gamma概率分布函数, 它的形状因子 $=2$, 最高 频率 $=-1 / \lambda$, 平均导管长度为 $-2 / \lambda_{\mathrm{v}}$ 。

5 个枝条的导管长度平均值即为每树种的平均 导管长度。

\subsection{7 木质部密度测定}

每个枝条取一定枝段, 测定枝段干质量和鲜体 积，则木质部密度 $\left(D_{\mathrm{t}}\right)$ (Hacke et al., 2001) 为:

$D_{\mathrm{t}}=$ 干质量/鲜体积

5 个枝条的木质部密度平均值即为每树种的平 均木质部密度。

\section{4 数据处理}

采用Microsoft Office Excel 2003对数据进行预 处理, 采用SPSS 18.0对不同特征值进行单因素方差 分析(ANOVA), 最小显著性差异 ( $L S D$ )法进行差异 显著性检验, $p<0.01$ 表示极显著性差异。对不同特 征值进行线性分析, $t$ 值越大影响越显著。相关图表 制作在Excel中完成。

\section{2 结果和分析}

\section{1 栓塞脆弱性}

各树种 $P_{50}$ 值及木质部结构特征值见表 1 。刺槐、 沙棘和榆树的栓塞脆弱曲线均为 “ $\mathrm{r}$ ”形(图1), 即在 水分胁迫下，随着水势不断下降，木质部的导水能 力急剧下降，木质部立即发生栓塞。旱柳、元宝枫 和榛的栓塞脆弱曲线均为“s”形(图2), 在水分胁迫 条件下，当压力在一定范围内逐渐增大时，其导水 率损失维持在原有水平, 只有当压力增大到一定程 度或水分亏缺达到一定程度时植物才发生栓塞, 导 水率损失逐渐增大。6 6 个耐旱树种栓塞脆弱性 $\left(P_{50}\right)$ 大小顺序为: 刺槐 $>$ 榆树 $>$ 沙棘 $>$ 旱柳 $>$ 元宝枫 $>$ 榛, 其中刺槐的 $P_{50}$ 值最大 $((-0.22 \pm 0.026) \mathrm{MPa})$, 榛的 最小 $((-2.84 \pm 0.054) \mathrm{MPa})($ 表1 $), P_{50}$ 值越大, 植物越 易栓塞，因此，沙棘、刺槐和榆树抗栓塞性较旱柳、 元宝枫和榛的小，其中栓塞脆弱曲线为“ “s”形树种 榛抗栓塞性最大, 元宝枫次之, 旱柳最小, 栓塞脆 弱曲线为 “ $\mathrm{r}$ ”形树种沙棘抗栓塞性最大, 榆树次之, 刺槐最小。对6树种栓塞脆弱性进行差异显著性分 析, 结果表明脆弱曲线为““””形和“ $“ \mathrm{~s}$ ”形的树种 $P_{50}$ 值 差异极显著 $(p<0.01)$, 其中, 脆弱曲线为“"r“形的树 种中, 沙棘与刺槐、榆树的 $P_{50}$ 值差异也极显著 $(p<$ 0.01) (表1)。

\section{2 木质部结构}

\subsection{1 导管直径}

各树种一年生枝条平均导管直径大小顺序为: 刺槐 $>$ 榆树 $>$ 旱柳 $>$ 元宝枫 $>$ 榛 $>$ 沙棘, 其中除沙棘导 管直径最小 $((23.57 \pm 0.579) \mu \mathrm{m})$ 外(表1)，刺槐、榆树 


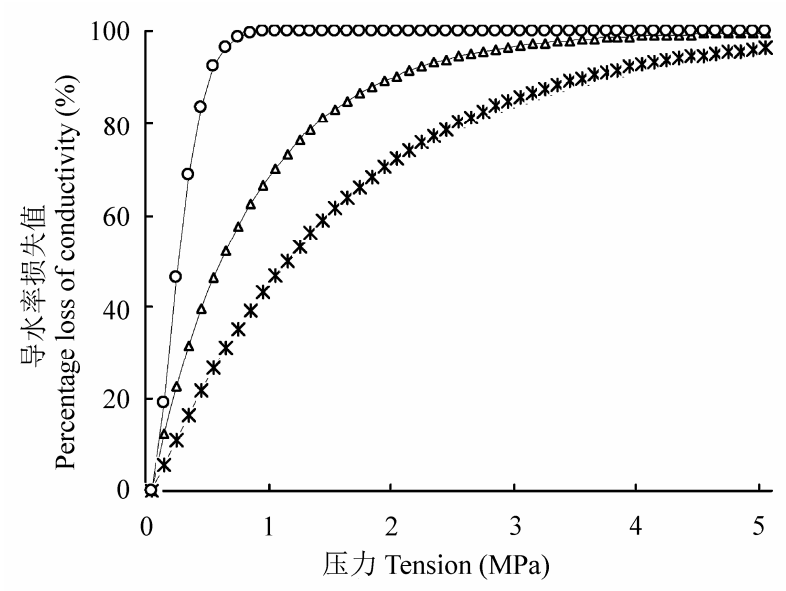

图1 耐旱树种沙棘 $(*)$ 、刺槐 $(O)$ 、榆树 $(\triangle)$ 的栓塞脆弱曲线 (" $\mathrm{r}$ "形)。

Fig. 1 The vulnerability curves of Hippophae rhamnoides $(*)$, Robinia pseudoacacia $(\bigcirc)$ and Ulmus pumila $(\triangle)$ ("ro" shape).

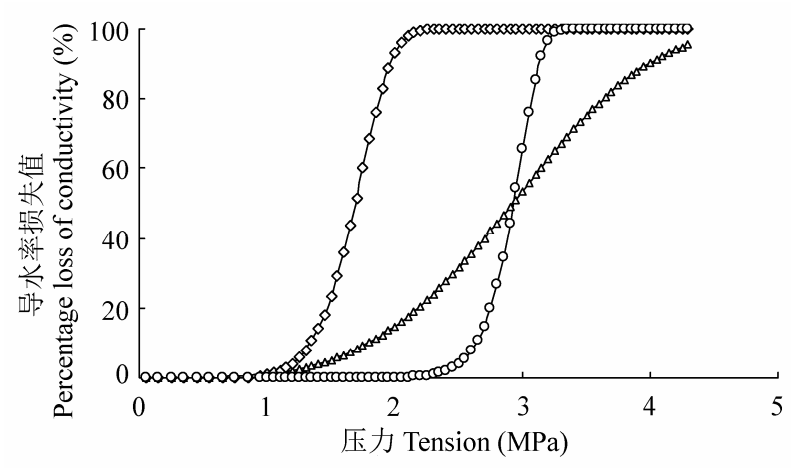

图2 而旱树种元宝枫 $(\triangle)$ 、旱柳 $(\diamond)$ 、榛 $(\bigcirc)$ 的栓塞脆弱曲线 ("s"形)。

Fig. 2 The vulnerability curves of Acer truncatum $(\triangle)$, Salix matsudana $(\diamond)$ and Corylus heterophylla $(\bigcirc)$ ("s" shape).

导管直径大于旱柳、元宝枫和榛的导管直径, 且只 除沙棘外，导管直径大小顺序与其 $P_{50}$ 顺序一致，即 随着导管直径的增大, $P_{50}$ 值也增大, 说明导管直径 越大, 植物栓塞脆弱性越大, 即各树种越易发生栓 塞。对6个耐旱树种导管直径进行差异显著性分析表 明: 脆弱曲线为 “ $r$ ”形的刺槐、沙棘和榆树的导管直 径与脆弱曲线为“s”形的旱柳、元宝枫和榛的导管直 径差异极显著 $(p<0.01)$ (表1), 导管直径间有显著性 差异, 其 $P_{50}$ 值间也具显著性差异, 可见导管直径差 异性显著与否决定其栓塞脆弱性差异性显著与否。 同时，线性分析结果表明: 导管直径大小对木质部 栓塞脆弱性有决定性作用 $(t=0.532)$ (表2)。

\subsection{2 导管内径跨度}

各树种一年生枝条平均导管内径跨度的大小顺
序为: 刺槐 $>$ 榆树 $>$ 沙棘 $>$ 旱柳 $>$ 元宝枫 $>$ 榛 $($ 表 1$), 6$ 个 树种导管内径跨度顺序与其 $P_{50}$ 顺序一致, 即随着 木质部导管内径跨度的增大, $P_{50}$ 值增大, 植物栓塞 程度增强。对6树种导管内径跨度进行差异显著性分 析表明: 脆弱曲线为““”形的刺槐、沙棘和榆树与脆 弱曲线为“s”形的旱柳、元宝枫和榛的导管内径跨度 差异极显著 $(p<0.01)$ (表1), 且线性分析表明, 导管 内径跨度对 $P_{50}$ 影响很大 $(t=0.306)($ 表 2$)$, 可见导管 内径跨度的大小对 6 个耐旱树种的栓塞脆弱性有一 定影响。

\subsection{3 导管密度}

各树种一年生枝条平均导管密度大小顺序为: 旱柳 $>$ 榛>沙棘 $>$ 元宝枫 $>$ 榆树>刺槐, 除沙棘 $(216.52$ \pm 0.006 )外(表1), 脆弱曲线为“s”形的旱柳、榛和元 宝枫的导管密度显著大于脆弱曲线为“ “ 和刺槐, 沙棘、刺槐和榆树的导管密度顺序与其 $P_{50}$ 顺序相反, 即随着导管数目的减小, $P_{50}$ 值增大, 植 物栓塞程度增强。对 6 个耐旱树种导管密度进行差异 显著性分析表明: 脆弱曲线为“ “ $\mathrm{r}$ ”形的刺槐、沙棘和 榆树与脆弱曲线为“s”形的旱柳、元宝枫和榛导管密 度差异极显著 $(p<0.01)$ (表1), 其中, 脆弱曲线为“ $r$ ” 形的沙棘与刺槐和榆树差异也极显著 $(p<0.01)$ (表 $1)$, 导管密度的大小影响 6 个耐旱树种的栓塞脆弱 性 $(t=0.265)$ (表2)。

\subsection{4 导管连接度}

各树种一年生枝条导管连接度大小顺序为: 元 宝枫 $>$ 榛 $>$ 旱柳 $>$ 榆树 $>$ 沙棘 $>$ 刺槐 (表 1 ), 随着导管连 接度的增大, 脆弱曲线为“s”形的元宝枫、榛和旱柳 的 $P_{50}$ 减小, 则植物不易栓塞, 而脆弱曲线为“ “ $\mathrm{r}$ ”形的 树种则无此规律。对 6 个耐旱树种导管连接度进行差 异显著性分析，结果表明脆弱曲线为“ $\mathrm{r}$ ”形的刺槐、 沙棘和榆树与脆弱曲线为“s”形的旱柳、元宝枫和榛 导管连接度差异极显著 $(p<0.01)$ (表1), 各树种 $P_{50}$ 值也差异极显著, 导管连接度的大小对 6 个耐旱树 种的抗栓塞性差异有影响 $(t=0.188)$, 但影响不大。

\subsection{5 导管长度}

各树种一年生枝条平均导管长度大小顺序(表 1)为: 刺槐 $>$ 榆树 $>$ 沙棘 $>$ 旱柳 $>$ 榛 $>$ 元宝枫, 其中刺 槐的导管长度最大, 为 $(20.55 \pm 1.917) \mathrm{cm}$, 其 $P_{50}$ 值 也最大, 元宝枫的导管长度最小, 为 $(3.08 \pm 0.253)$ $\mathrm{cm}$, 其 $P_{50}$ 值接近最小, 除榛和元宝枫对调外, 导管 长度的顺序与 $P_{50}$ 的顺序一致, 即随着导管长度的 
表1 6 个耐旱树种 $50 \%$ 导水率损失的压力值 $\left(P_{50}\right)$ 及木质部结构特征值(平均值土标准误差)

Table 1 The value of tension at $50 \%$ loss of conductivity $\left(P_{50}\right)$ and characteristic values of xylem structure of the six species (mean $\pm S E$ ) 因子 Parameter 耐旱树种 Drought tolerance trees

\begin{tabular}{|c|c|c|c|c|c|c|}
\hline & $\begin{array}{c}\text { 沙棘 } \\
\text { Hippophae } \\
\text { rhamnoides }\end{array}$ & $\begin{array}{c}\text { 刺槐 } \\
\text { Robinia } \\
\text { pseudoacacia }\end{array}$ & $\begin{array}{c}\text { 榆树 } \\
\text { Ulmus } \\
\text { pumila }\end{array}$ & $\begin{array}{c}\text { 元宝枫 } \\
\text { Acer } \\
\text { truncatum }\end{array}$ & $\begin{array}{c}\text { 早柳 } \\
\text { Salix } \\
\text { matsudana }\end{array}$ & $\begin{array}{c}\text { 榛 } \\
\text { Corylus } \\
\text { heterophylla }\end{array}$ \\
\hline$P_{50}(\mathrm{MPa})$ & $-1.31 \pm 0.183^{\mathrm{Ab}}$ & $-0.22 \pm 0.026^{\mathrm{Ac}}$ & $-0.55 \pm 0.064^{\mathrm{Ac}}$ & $-2.64 \pm 0.214^{\mathrm{Ba}}$ & $-1.55 \pm 0.103^{\mathrm{Bb}}$ & $-2.84 \pm 0.054^{\mathrm{Ba}}$ \\
\hline 导管直径 & $23.57 \pm 0.579^{\mathrm{Ac}}$ & $56.96 \pm 1.913^{\mathrm{Aa}}$ & $49.48 \pm 1.206^{\mathrm{Aa}}$ & $31.26 \pm 0.405^{\mathrm{Bb}}$ & $32.11 \pm 0.415^{\mathrm{Bb}}$ & $26.81 \pm 0.319^{\mathrm{Bc}}$ \\
\hline $\begin{array}{l}\text { Vessel diameter }(\mu \mathrm{m}) \\
\text { 导管内径跨度 } \\
\text { Conduit wall span (um) }\end{array}$ & $40.10 \pm 1.651^{\mathrm{Aa}}$ & $62.20 \pm 0.905^{\mathrm{Ab}}$ & $58.07 \pm 2.414^{\mathrm{Aa}}$ & $34.29 \pm 0.729^{\mathrm{Bb}}$ & $36.19 \pm 0.583^{\mathrm{Bc}}$ & $27.04 \pm 0.749^{\mathrm{Bb}}$ \\
\hline 导管密度 & $216.52 \pm 0.006^{\mathrm{Ab}}$ & $32.22 \pm 2.588^{\mathrm{Aa}}$ & $53.64 \pm 0.011^{\mathrm{Aa}}$ & $143.55 \pm 3.874^{\mathrm{Bb}}$ & $284.37 \pm 0.015^{\mathrm{Bb}}$ & $270.11 \pm 0.013^{\mathrm{Bb}}$ \\
\hline 导管连接度 & $0.03 \pm 0.006^{\mathrm{Aa}}$ & $0.02 \pm 0.002^{\mathrm{Aa}}$ & $0.04 \pm 0.004^{\mathrm{Aa}}$ & $0.13 \pm 0.008^{\mathrm{Bb}}$ & $0.07 \pm 0.007^{\mathrm{Bb}}$ & $0.10 \pm 0.008^{\mathrm{Bb}}$ \\
\hline $\begin{array}{l}\text { Contact fraction } \\
\text { 导管长度 } \\
\text { Vessel length }(\mathrm{cm})\end{array}$ & $13.35 \pm 0.827^{\mathrm{Ab}}$ & $20.55 \pm 1.913^{\mathrm{Aa}}$ & $17.23 \pm 0.834^{\mathrm{Aa}}$ & $3.08 \pm 0.253^{\mathrm{Bc}}$ & $4.10 \pm 0.397^{\mathrm{Bc}}$ & $3.23 \pm 0.223^{\mathrm{Bc}}$ \\
\hline 木质部密度 & $1.54 \pm 0.086^{\mathrm{Aa}}$ & $1.17 \pm 0.129^{\mathrm{Aa}}$ & $1.17 \pm 0.062^{\mathrm{Aa}}$ & $1.42 \pm 0.167^{\mathrm{Ba}}$ & $1.46 \pm 0.209^{\mathrm{Ba}}$ & $0.83 \pm 0.039^{\mathrm{Bb}}$ \\
\hline
\end{tabular}

Wood density $\left(\mathrm{g} \cdot \mathrm{cm}^{-3}\right)$

不同大写字母表示脆弱曲线为“r”形的树种与脆弱曲线为“s”形的树种差异显著性 $(p<0.01)$; 不同小写字母表示各树种种间差异显著性 $(p<0.01)$ 。 Different capital letters indicate significant difference $(p<0.01)$ between trees of " $\mathrm{r}$ " and " $\mathrm{s}$ " shape and lowercase letters (a or b) indicate significant difference $(p<0.01)$ of trees by each species.

表2 6 个耐旱树种木质部结构特征值对 $50 \%$ 导水率损失的压力值 $\left(P_{50}\right)$ 的 影响程度

Table 2 The significance in characteristic values of xylem structure to value of tension at $50 \%$ loss of conductivity $\left(P_{50}\right)$

\begin{tabular}{|c|c|c|}
\hline 因子 Parameters & 系数 Coefficient & $t$ \\
\hline 木质部密度 Wood density $\left(\mathrm{g} \cdot \mathrm{cm}^{-3}\right)$ & 0.326 & 0.702 \\
\hline 导管直径 Vessel diameter ( $\mu \mathrm{m})$ & 0.037 & 0.532 \\
\hline 导管内径跨度 Conduit wall span $(\mu \mathrm{m})$ & -0.071 & 0.306 \\
\hline 导管密度 Number of vessels per unit area & -0.007 & 0.265 \\
\hline 导管连接度 Contact fraction & -19.762 & 0.188 \\
\hline 导管长度 Vessel length $(\mathrm{cm})$ & -0.281 & 0.010 \\
\hline
\end{tabular}

$t$ 表示各因子对 $P_{50}$ 的影响程度, $t$ 值越大影响越显著。

$t$ indicates that the influence of each factor to $P_{50}$, the greater the $t$ value, the more significant to $P_{50}$.

增加, 其 $P_{50}$ 值也增大, 植物栓塞程度增强。对 6 个耐 旱树种导管长度进行差异性分析表明: 脆弱曲线为 “ $\mathrm{r}$ ”形的刺槐、沙棘和榆树与脆弱曲线为“s”形的旱 柳、元宝枫和榛导管长度差异极显著 $(p<0.01)$ (表1), 其中, 脆弱曲线为“ “ $\mathrm{r}$ ”形的沙棘与刺槐和榆树导管长 度差异也极显著 $(p<0.01)$ (表1), 但线性分析表明: 导管长度对 $P_{50}$ 的影响最小 $(t=0.010)$ (表 2$)$ 。

\subsection{6 木质部密度}

各树种一年生枝条平均木质部密度大小顺序 为: 沙棘 $>$ 旱柳 $>$ 元宝枫 $>$ 刺槐 $=$ 榆树 $>$ 榛, 其中沙棘 的木质部密度最大 $\left((1.54 \pm 0.086) \mathrm{g} \cdot \mathrm{cm}^{-3}\right)$, 榛的最 小 $\left((0.83 \pm 0.039) \mathrm{g} \cdot \mathrm{cm}^{-3}\right)$ (表1), 脆弱曲线为“ “ $\mathrm{r}$ ”形的 沙棘、刺槐和榆树的木质部密度顺序恰好与其 $P_{50}$ 大小顺序相反, 而脆弱曲线为“s”形的旱柳、元宝枫 和榛的木质部密度顺序与其 $P_{50}$ 顺序相一致。随木质
部密度的增大, 沙棘、刺槐和榆树的 $P_{50}$ 值降低, 树 种栓塞抵抗力增强。对 6 个耐旱树种木质部密度进行 差异性分析表明：脆弱曲线为“s”形的榛与其余树 种的木质部密度差异极显著 $(p<0.01)$ (表1), 且线性 分析表明: 木质部密度对栓塞脆弱性的影响最大 $(t$ $=0.702)($ 表2 $)$ 。

\section{3 结论和讨论}

6 个耐旱树种栓塞脆弱性与木质部结构密切相 关。沙棘、刺槐和榆树的栓塞脆弱曲线为“ “ $\mathrm{r}$ ”形, 而 旱柳、元宝枫和榛的栓塞脆弱曲线为“s”形, 脆弱曲 线为“ “ $\mathrm{r}$ “形的树种与脆弱曲线为” $\mathrm{s}$ “形的树种 $P_{50}$ 值差 异极显著 $(p<0.01)$ 。木质部结构间的差异影响各树 种的栓塞脆弱性, 其中, 木质部密度影响最大 $(t=$ $0.702)$, 导管直径次之 $(t=0.532)$, 导管长度影响最 小 $(t=0.01)$ 。

沙棘、刺槐和榆树的栓塞脆弱曲线为“ $\mathrm{r}$ ”形(图 1), 旱柳、元宝枫和榛的栓塞脆弱曲线为“s”形(图2), 这与Sperry等(2012)提出的植物木质部栓塞脆弱曲 线的两种形式相符。沙棘、刺槐和榆树在水分胁迫 条件下, 随着水势下降, 其木质部导水能力随之急 剧下降, 木质部立即发生栓塞, 而早柳、元宝枫和榛 在水分胁迫条件下, 当压力在一定范围内逐渐增大 时, 其导水率损失维持在原有水平, 只有水分亏缺 达到一定程度时木质部才发生栓塞，导水率损失逐 渐增大。沙棘、刺槐和榆树(“" ””形)较旱柳、元宝枫 和榛(“s”形)之所以易发生栓塞, 有以下原因: 
一是因为刺槐和榆树导管直径较旱柳、元宝枫 和榛的导管直径大, 这与前人的具有大径导管植物 比小径导管植物更易栓塞观点相同(Wheeler et al., 2005; Hacke et al., 2006; Markesteijn et al., 2011; Cai et al., 2010b; 张海昕等, 2013), 刺槐和榆树之所以 容易栓塞是气种假说(air-seeding hypothesis)机理中 的导管壁间纹孔膜的表面积所决定的(Wheeler et $a l .$, 2005), 纹孔膜在木质部水分传导过程中充当重 要的角色, 其上有大量的微孔, 是水流从一个导管 (管胞)流向另一个导管(管胞)的入口(Choat et al., 2007; Loepfe et al., 2007), 纹孔面积假说 (pit area hypothesis) 又是气种假说的必然结果, 按照气种假 说， $\mathrm{P}_{50}$ 值由导管上所有纹孔面积中具有最大孔洞的 纹孔决定, 因此, 导管直径越大, 导管上纹孔所占 面积越大, 纹孔膜上拥有 “易漏”的微孔的几率就越 高, 植物栓塞脆弱性就大。导管直径、导管壁上纹 孔面积与 $P_{50}$ 的相关性很接近 $\left(R^{2}\right.$ 介于 $\left.0.72-0.75\right)$, 它 们在水分运输的有效性与安全性间具有权衡性 (Wheeler et al., 2005, Cai et al., 2010b)。二是因为沙 棘、刺槐和榆树较早柳、元宝枫和榛的导管内径跨 度大, 导管内径跨度越大, 在负水势条件下导管腔 越易垮塌, 植物越易栓塞, 这与Hargrave等(1994)的 研究结果相同。三是因为沙棘、刺槐和榆树的木质 部导管密度小、导管连接度低, 而早柳、元宝枫和 榛则恰好相反, 在低水势条件下, 水分可通过相邻 导管或相邻导管壁纹孔进行水分运输, 而沙棘、刺 槐和榆树通过相邻导管或纹孔运输水分几率显著小 于旱柳、元宝枫和榛, 因此, 沙棘、刺槐和榆树较 其他三树种导管易发生栓塞, 这支持Hacke等(2006) 的研究结果。四是因为刺槐和榆树木质部密度小于 旱柳、元宝枫和榛, 木质部密度越小, 植物栓塞脆 弱性越大, 这也与前人研究结果(Hacke et al., 2001; Jacobsen et al., 2005)相同。此外, 沙棘、刺槐和榆 树与旱柳、元宝枫和榛相比, 前者较后者的导管直 径大、导管长度长, 植物运输水分速度快, 从而较 易发生栓塞。

脆弱曲线为“"r“形的沙棘导管直径最小, 木质部 密度、导管内径跨度却大于旱柳、元宝枫和榛, 因 此, 在低水势条件下导管腔易垮塌和被破坏, 其栓 塞脆弱性也就较大, 但沙棘的耐旱能力很强, 这可 能与其木质部其他结构有关, 如Cai等(2014)研究发 现沙棘为半环孔材, 不仅可通过相邻的导管间的纹
孔进行水分运输, 还可通过纤维管胞进行水分运输, 并提出“纤维桥假说” (fiber bridge hypothesis), 单独 的被纤维所包围的导管和纤维桥结构可能使其具有 良好的对水分亏缺的适应能力, 而且纤维可在极端 负水势条件下对抵御导管壁的破坏起重要作用 (Hacke et al., 2001; Jacobsen et al., 2005), 另外, 沙 棘的叶具有发达的表皮毛、厚的角质层和栅栏组织, 其根系具有很强的蓄水能力 (李代琼等, 2003), 沙棘 保护酶系统在低水势条件下能维持较高活性, 使活 性氧保持在较低水平(韩芯莲等, 2002), 这些可能都 是沙棘对水分适应的内在机制, 并且沙棘的木质部 密度最大, 大的密度可降低植物生长速度和枝条存 储水容量的成本(Enquist et al., 1999), 而且木质部 密度在某种程度上补偿了较低的木质部最大导水 率, 在水分较缺乏时, 植物可通过阻止气体交换、降 低光合速率来适应水分贵乏(West, 1989)。

Cochard等(1992)对几种耐旱的栋类树种栓塞 脆弱性研究表明, 有几种栎类树种在水分传导结构 上具有降低其导管内空穴化危险性的特征, 但也有 一个很耐旱的种Quercus robur具有很少的抗空穴化 结构特征。Vilagrosa (2002)和Vilagrosa等(2003)对 Pistacia lentiscus和Quercus coccifera的研究发现较 高的抗空穴化能力与较高存活率之间没有相关性。 张硕新等(1997)研究发现耐旱树种刺槐和沙棘不一 定是栓塞脆弱性小的、不容易发生栓塞的树种。本 研究结果进一步证实, 作为黄土高原造林树种的沙 棘和刺槐, 其抵御水分匮乏的能力很强, 但耐旱的 沙棘、刺槐和榆树木质部栓塞脆弱曲线呈““ $\mathrm{r}$ ”形, 意 味着当水势降低到某一阈值时, 其木质部的导水能 力急剧下降, 木质部导管很快发生栓塞, 通过木质 部栓塞降低其水分输导能力, 从而达到限流耐旱、 维持机体内水分平衡、保持树体正常生长发育的目 的。而旱柳、元宝枫和榛的栓塞脆弱曲线呈“s”形, 即在水分亏缺条件下, 导水率损失首先维持在一定 水平, 当水分亏缺达到一定程度时, 木质部才发生 栓塞, 导水率损失立即增大, 没有达到对水分限流 的目的。树木在遭遇水分等因子胁迫时, 可以通过 关闭气孔、减少叶面蒸发、渗透调节、保持膨压、 增加组织弹性等途径来抵御干旱。本研究结果来看, 沙棘、刺槐和榆树在遭遇水分胁迫时, 在一定的水 势范围内, 通过木质部导管发生栓塞来降低导水能 力, 从而减少水分丧失可能是其适应干旱条件的方 
式之一。沙棘、刺槐和榆树是栓塞脆弱性大、较易 发生栓塞的树种, 这与其自身的木质部结构密切相 关，如：导管直径大、导管长度长、导管密度小、 导管连接度低等, 这些因素恰好使得这些树种在水 势较低情况下易发生栓塞, 通过木质部栓塞来适应 低水势条件和环境的变化。但植物对水分胁迫的反 应不是一个单独的过程，也不仅是某些部位的反应， 而是一个复杂的具有综合反馈机制的调节系统(安 锋和张硕新, 2005), 这些树种在对环境长期的自我 调节和进化过程中, 通过形态和结构等多方面的内 部调节来适应外界环境条件的变化, 从而达到水分 运输过程中有效性与安全性的协调统一。因此, 还 需将植物栓塞脆弱性与根的导管、叶的解剖结构、 植物内部生理特性、生长量、生长速率和外界条件 等结合起来作进一步研究。

\section{基金项目 国家自然科学基金(31270646)。}

\section{参考文献}

An F, Zhang SX (2005). Studies of roots and shoots vulnerability to xylem embolism in seven woody plants. Acta Ecologica Sinica, 25, 1928-1933. (in Chinese with English abstract) [安锋, 张硕新 (2005). 七种木本植物根和 小枝木质部栓塞的脆弱性. 生态学报, 25, 1928-1933.]

Anderegg WRL, Plavcov L, Anderegg LDL, Hacke UG, Berry JA, Field CB (2013). Drought's legacy: Multi-year hydraulic deterioration underlies widespread aspen forest die-off and portends increased future risk. Global Change Biology, 19, 1188-1196.

Awad H, Barigah T, Badel E, Cochard H, Herbette S (2010). Poplar vulnerability to xylem cavitation acclimates to drier soil conditions. Physiologia Plantarum, 139, 280-288.

Cai J, Hacke U, Zhang S, Tyree MT (2010a). What happens when stems are embolized in a centrifuge? Testing the cavitron theory. Physiologia Plantarum, 140, 311-320.

Cai J, Li S, Zhang HX, Zhang SX, Tyree MT (2014). Recalcitrant vulnerability curves: Methods of analysis and the concept of fibre bridges for enhanced cavitation resistance. Plant, Cell \& Environment, 37, 35-44.

Cai J, Tyree MT (2010). The impact of vessel size on vulnerability curves: Data and models for within-species variability in saplings of aspen, Populus tremuloides Michx. Plant, Cell \& Environment, 33, 1059-1069.

Cai J, Zhang SX, Tyree MT (2010b). A computational algorithm addressing how vessel length might depend on vessel diameter. Plant, Cell \& Environment, 33, 12341238.

Chaves MM, Pereira JS, Maroco J, Rodriggues ML, Ricardo CPP, Osorio ML (2002). How plants cope with water stress in the field? Photosynthesis and growth. Annals of
Botany, 89, 907-916.

Choat B, Cobb AR, Jansen S (2007). Structure and function of bordered pits: New discoveries and impacts on whole-plant hydraulic function. New Phytologist, 177, 608-626.

Choat B, Jansen S, Brodribb TJ, Cochard H, Delzon S, Bhaskar R, Bucci SJ, Feild TS, Gleason SM, Hacke UG (2012). Global convergence in the vulnerability of forests to drought. Nature, 491, 752-755.

Cochard H (2002). A technique for measuring xylem hydraulic conductance under high negative pressures. Plant, Cell \& Environment, 25, 815-819.

Cochard H, Barigah S, Kleinhentz M, Eshel A (2008). Is xylem cavitation resistance a relevant criterion for screening drought resistance among Prunus species? Plant Physiology, 165, 976-982.

Cochard H, Bréda N, Granier A, Aussenac G (1992). Vulnerability to air embolism of three European oak species (Quercus petraea (Matt) Liebl, Q. pubescens Willd, Q. robur L). Annals of Forest Science, 49, 225-233.

Cochard H, Damour G, Bodet C, Tharwat I, Poirier M, Améglio $\mathrm{T}$ (2005). Evaluation of a new centrifuge technique for rapid generation of xylem vulnerability curves. Physiologia Plantarum, 124, 410-418.

Cochard H, Lens F, Tixier A, Sperry JS , Jansen S, Herbette S (2013). Embolism resistance as a key mechanism to understand adaptive plant strategies. Plant Biology, 16, 287-292.

Cohen S, Bennink J, Tyree M (2003). Air method measurements of apple vessel length distributions with improved apparatus and theory. Journal of Experimental Botany, 54, 1889-1897.

Delzon S, Douthe C, Sala A, Cochard H (2010). Mechanism of water-stress induced cavitation in conifers: Bordered pit structure and function support the hypothesis of seal capillary-seeding. Plant, Cell \& Environment, 33, 21012111.

Enquist BJ, West GB, Charnov EL, Brown JH (1999). Allometric scaling of production and life-history variation in vascular plants. Nature, 401, 907-911.

Fichot R, Barigah TS, Chamaillard S, lethiec D, Laurans F, Cochard H, Brignolas F (2010). Common trade-offs between xylem resistance to cavitation and other physiological traits do not hold among unrelated Populus deltoides $\times$ Populus nigra hybrids. Plant, Cell \& Environment, 33, 1553-1568.

Gullo MA, Salleo S, Piaceri EC, Rosso R (1995). Relations between vulnerability to xylem embolism and xylem conduit dimensions in young trees of Quercus corris. Plant, Cell \& Environment, 18, 661-669.

Hacke UG, Jansen S (2009). Embolism resistance of three boreal conifer species varies with pit structure. New Phytologist, 182, 675-686.

Hacke UG, Jacobsen AL, Pratt RB (2009). Xylem function of

www.plant-ecology.com 
arid-land shrubs from California, USA: An ecological and evolutionary analysis. Plant, Cell \& Environment, 32, 1324-1333.

Hacke UG, Sperry JS, Field TS (2007). Water transport in vessel less angiosperms: Conducting efficiency and cavitation safety. International Journal of Plant Sciences, 168, 1113-1126.

Hacke UG, Sperry JS, Pockman WT, Davis SD, McCulloh KA (2001). Trends in wood density and structure are linked to prevention of xylem implosion by negative pressure. Oecologia, 126, 457-461.

Hacke UG, Sperry JS, Wheeler JK, Castro L (2006). Scaling of angiosperm xylem structure with safety and efficiency. Tree Physiology, 26, 689-701.

Han RL, Li LX, Liang ZS, Xue ZD, Du ZK (2002). The research of Hippophae rhamnoides membrane lipid peroxide under drought stress protection system. Journal of Northwest Forestry College, 17, 1-5. (in Chinese with English abstract) [韩荵莲, 李丽霞, 梁宗锁, 薛智德, 杜 正科 (2002). 干旱胁迫下沙棘膜脂过氧化保护体系研 究. 西北林学院学报, 17, 1-5.]

Hargrave KR, Kolb KJ, Ewers FW, Davis SD (1994). Conduit diameter and drought-induced embolism in Salvia mellifera (Labiatae). New Phytologist, 126, 695-705.

Jacobsen AL, Ewers FW, Pratt RB, Paddock WA, Davis SD (2005). Do xylem fibers affect vessel cavitation resistance? Plant Physiology, 139, 546-556.

Lemoine D, Cochard H, Granier A (2002). Within crown variation in hydraulic architecture in beech (Fagus sylvatica L.): Evidence for a stomatal control of xylem embolism. Annals of Forest Science, 59, 19-27.

Li DQ, Liang YM, Huang J, Jiang J (2003). Study on characteristic of anatomy in Hippophae rhamnoides subsp. sinensis. Journal of Northwest Forestry College, 23, 1224-1230. (in Chinese with English abstract) [李代琼, 梁一民, 黄瑾, 姜峻 (2003). 沙棘的形态解剖学特性研 究. 西北植物学报, 23, 1224-1230.]

Loepfe L, Martinez-Vilalta J, Pinol J, Mencuccini M (2007). The relevance of xylem network structure for plant hydraulic efficiency and safety. Theoretical Biology, 247, 788-803.

Maherali H, Pockman WT, Jackson RB (2004). Adaptive variation in the vulnerability of woody plants to xylem cavitation. Ecology, 85, 2184-2199.

Markesteijn L, Poorter L, Paz H, Sack L, Bongers F (2011). Ecological differentiation in xylem cavitation resistance is associated with stem and leaf structural traits. Plant, Cell \& Environment, 34, 137-148.

Nahm M, Matzarakis A, Rennenberg H, Geßler A (2007). Seasonal courses of key parameters of nitrogen, carbon and waterbalance in European beech (Fagus sylvatica L.) grown on four different study sites along a European North-South climate gradient during the 2003 drought.
Trees, 21, 79-92.

Rennenberg H, Loreto F, Polle A, Brilli F, Fares S, Beniwal RS (2006). Physiological responses of forest trees to heat and drought. Plant Biology, 8, 556-571.

Rosner S, Klein A, Müller U (2007). Hydraulic and mechanical properties of young Norway spruce clones related to growth and wood structure. Tree Physiology, 27, 1165-1178.

Sperry JS, Christman MA, Torres-ruiz JM, Taneda H, Smith DD (2012). Vulnerability curves by centrifugation: Is there an open vessel artefact, and are ' $r$ ' shaped curves necessarily invalid? Plant, Cell \& Environment, 35, 601-610.

Sperry JS, Hacke UG, Pittermann J (2006). Size and function in conifer tracheids and angiosperm vessels. Botany, 93, 1490-1500.

Tyree MT, Sperry JS (1989). Vulnerability of xylem to cavitation and embolism. Annual Review of Plant Biology, 40, 19-36.

Tyree MT, Zimmermann MH (2002). Xylem Structure and the Ascent of Sap. Springer, Berlin. 45-56.

Vilagrosa A (2002). Estrategias de resistencia al deficit hídrico en Pistacia lentiscus L. y Quercus coccifera L. Implicaciones en la repoblación forestal. $\mathrm{PhD}$ dissertation, University of Alicante, Alicante, Spain.

Vilagrosa A, Bellot J, Vallejo VR, Gil-Pelegrín E (2003). Cavitation, stomatal conductance and leaf dieback in seedlings of two co-occurring Mediterranean shrubs during an intense drought. Experimental Botany, 54, 2015-2024.

West NE (1989). Intermountain deserts, shrub steppes, and wood-lands. In: Barbour MG, Billings WD eds. North American Terrestrial Vegetation. Cambridge University Press, Cambridge, UK. 209-230.

Wheeler JK, Sperry JS, Hacke UG, Hoang N (2005). Inter-vessel pitting and cavitation in woody Rosaceae and other vesselled plants: A basis for a safety versus efficiency trade-off in xylem transport. Plant, Cell \& Environment, 28, 800-812.

Zhang HX, Li S, Zhang SX, Xiong XY, Cai J (2013). Relationships between xylem structure and embolism vulnerability in four Populus clones. Scientia Silvae Sinicae, 49(5), 54-61. (in Chinese with English abstract) [张海昕, 李珊, 张硕新, 熊晓燕, 蔡靖 (2013). 4个杨树 无性系木质部导管结构与栓塞脆弱性的关系. 林业科 学, 49(5), 54-61.]

Zhang SX, Shen WJ, Zhang YY, Zhou XX (1997). The research on the xylem embolism vulnerability of several woody plants. Journal of Northwest Forestry College, 12(2), 1-6. (in Chinese with English abstract) [张硕新, 申 卫军, 张远迎, 周新霞 (1997). 几个抗旱树种木质部栓 塞脆弱性的研究. 西北林学院学报, 12(2), 1-6.]

责任编委: 冯兆忠 责任编辑: 李 敏 


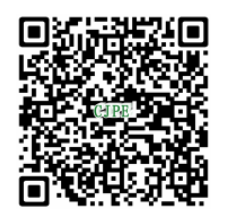

植物生态学报官网

唯一投稿网址

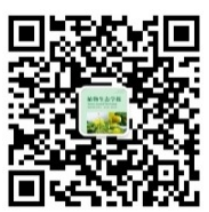

微信订阅号

期刊及学科

相关信息发布

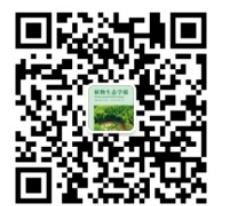

微信服务号

稿件状态查询

全文检索浏览 